\title{
ACESSO À JUSTIÇA COMO ENFOQUE NA FORMAÇÃO JURÍDICA PARA AS FORMAS CONSENSUAIS DE SOLUÇÃO DE CONFLITOS
}

\author{
William Paiva Marques Júnior* \\ Larissa de Alencar Pinheiro Macedo*
}

\section{RESUMO}

Este artigo propõe-se estudar a educação jurídica como ambiência de fomento do acesso à justiça. Na primeira seção, faz-se um estudo do Projeto Florença e das ondas de acesso à justiça. Na segunda, aborda-se o acesso à justiça como um direito humano e fundamental. Por fim, destaca-se o liame entre o acesso à justiça e a educação jurídica, com a formação de profissionais voltados para a modulação das formas consensuais de solução de conflitos. Conclui-se que a educação jurídica assume um papel vetorial na efetividade do acesso à justiça. A metodologia é qualitativa, de natureza pura e com objetivo exploratório.

Palavras-chave: Acesso à Justiça. Projeto Florença. Direitos Humanos. Educação Jurídica. Formas Consensuais de Resolução de Conflitos.

\section{ACCESS TO JUSTICE AS A FOCUS ON LEGAL TRAINING FOR}

\section{CONSENSUS WAYS TO SOLVE CONFLICTS}

\begin{abstract}
This article proposes to study legal education as an environment to promote access to justice. In the first section, the study is about the Florence Project and waves of access to justice. In the second, access to justice is approached as a human and fundamental right. Finally, the link between access to justice and legal education is highlighted, with the training of professionals focused on modulating consensual forms of conflict resolution. It's concluded that legal education assumes a vector role in the effectiveness of access to justice. The methodology is qualitative, of a pure nature and with an exploratory objective.
\end{abstract}

Keywords: Access to Justice. Florence Project. Humans Right. Legal Education. Consensual

\footnotetext{
* Doutor e Mestre em Direito Constitucional pela UFC. Professor Adjunto I do Departamento de Direito Privado da Faculdade de Direito da UFC de Direito Civil II (Direito das Obrigações) e Direito Civil V (Direito das Coisas). Coordenador da Graduação em Direito da UFC (2014 a 2017). Assessor do Reitor da UFC. Docente do Programa de Pós-Graduação em Direito da UFC das disciplinas de Metodologia do Ensino Jurídico, Metodologia da Pesquisa Jurídica e Direito das Relações Internacionais e Contemporaneidade. Foi Advogado Júnior da ECT (Empresa Brasileira de Correios e Telégrafos), de 2008 a 2011. E-mail: williamarques.jr@gmail.com . Endereço postal: Avenida da Universidade, 2853, Bairro: Benfica, Fortaleza CE, CEP: 60020-181, Gabinete do Reitor da UFC.

* Mestranda em Direito Constitucional pela UFC, MBA em Gestão Empresarial pela FGV, Advogada inscrita na OAB/CE. E-mail: larissadealencarpinheiro@gmail.com. Endereço postal: Rua Doutor Gilberto Studart, 55, salas 907-909, Torre Sul, Bairro: Cocó, Fortaleza - CE, CEP: 60192-095, Alencar Macedo Advogados Associados.
} 
Forms of Conflict Resolution.

\section{INTRODUÇÃO}

O Projeto Florença exerce uma função instrumental na análise das ondas de acesso à justiça (CAPPELLETI, GARTH, 1988), destacando a importância desta pesquisa para a comunidade científica; as transformações sobre o entendimento acerca deste direito, estabelece as bases teóricas, bem como a amplitude conceitual do termo e suas consequências para o sistema jurídico.

Nesta seara, através do desenvolvimento de estudos sobre a temática, identificou-se que a quarta onda do movimento de acesso à justiça traz luz à perspectiva de que o enfoque deve ser dado não somente ao cidadão, mas ao acesso dos juristas. Ou seja, a problemática do presente artigo se atém a responder aos seguintes questionamentos: 1. De que forma está se formando os profissionais do direito para serem instrumentos de garantia da efetivação da justiça para a comunidade? 2. Como a formação acadêmica do estudante de direito contribui para o acesso à justiça?

Partindo desta compreensão, analisa-se a construção valorativa do acesso à justiça na ordem internacional, como um direito humano, e sua abordagem em diversos documentos internacionais, bem como sua transição de princípio para regra positivada no ordenamento jurídico brasileiro e a capilaridade deste acesso na promoção da justiça substantiva.

Em relação aos aspectos metodológicos, trata-se de uma pesquisa com abordagem qualitativa, de natureza pura. Quanto aos objetivos, esta pesquisa tem caráter exploratório, de pesquisa do tipo bibliográfica, por meio da análise de livros, artigos jurídicos, documentos e legislação.

Ao final, procura-se estabelecer o liame entre o acesso à justiça e a educação jurídica, pressupondo-se a formação do estudante de Direito como instrumento de transformação da realidade social, por meio de um ensino de abordagem pós-crítica e que permita ao aluno entender o potencial de sua atuação profissional para a sociedade, abrindo caminhos para novos enfoques na modulação de formas consensuais de solução de conflitos e na efetivação do acesso à justiça.

\section{PROJETO FLORENÇA E AS ONDAS DE ACESSO À JUSTIÇA}

O Florence Project (Projeto Florença) de pesquisa sobre o acesso à justiça foi coordenado por Mauro Cappelletti e Bryant Garth, financiado pela Ford Foundation, tendo sido publicado o volume III da versão final em 1978 (JUNQUEIRA, 1996). No Brasil, no ano 
de 1998, foi publicado o ensaio que serviu de introdução geral aos demais volumes da pesquisa sob o título de "Acesso à Justiça".

O projeto de Cappelletti e Garth (1988), foi inovador ao tratar sobre experiências de acesso à justiça, desenvolvendo uma pesquisa comparativa em diversos países (SADEK, 2014), por meio da integração de pesquisadores de várias áreas e juristas de múltiplas origens (JUNQUEIRA, 1996), estando a América Latina representada por México, Chile, Colômbia e Uruguai (CAVALCANTI, 1999).

A expressão "acesso à Justiça" "é reconhecidamente de difícil definição, mas serve para determinar duas finalidades básicas do sistema jurídico, entendendo este como o sistema pelo qual as pessoas podem reivindicar seus direitos e/ou resolver seus litígios sob os auspícios do Estado. Como primeira finalidade, o sistema deve ser acessível a todos; e, segunda, ele deve produzir resultados que sejam individual e socialmente justos (CAPPELLETI, GARTH, 1988).

Acesso à justiça é um direito basilar, pois sem ele nenhum dos demais direitos se efetiva. Por essa razão, qualquer ameaça ao acesso à justiça comina em sérios prejuízos aos princípios da igualdade e à prevalência da lei (SADEK, 2014), tendo o seu estudo como pressuposto a expansão e aprofundamento dos objetivos e métodos da moderna ciência jurídica (CAPPELLETI; GARTH, 1988).

Nos Estados liberais burgueses dos séculos XVIII e XIX os métodos utilizados para a solução dos litígios revelavam uma filosofia individualista dos direitos. Direito ao acesso à proteção judiciária representava fundamentalmente o direito formal do cidadão de petição ao Poder Judiciário. Afirmava-se que, como o acesso à justiça era um “direito natural”, estes não precisavam de uma ação do Estado para sua salvaguarda (CAPPELLETTI; GARTH, 1988).

No final do século dezenove e início do século vinte, observa-se uma mudança de paradigma social, abandonando-se a visão individualista dos direitos e reconhecendo-se os direitos sociais e deveres do Estado de assegurá-los, por meio de sua atuação positiva. Gradualmente, o efetivo acesso vem sendo reconhecido como de importância fundamental entre os novos direitos individuais e sociais, tendo em vista que a titularidade de direitos é

\footnotetext{
${ }^{1}$ Nesta esteira, o próprio termo acesso à Justiça pode ser objeto de discussão, pois há dúvidas se a expressão trata do acesso ao Poder Judiciário, às instâncias legais e estatais de solução de conflitos, ou de assegurar que todos consigam ter suas disputas jurídicas resolvidas justamente (e, nesse caso, justiça é tomada como um valor, e não como um organismo estatal)? Em verdade, o parâmetro geralmente foi ao acesso às instâncias oficiais (estatais ou não, já que se inserem as experiências sociais de resolução de conflitos), e não ao valor justiça (JUNQUEIRA, 1996).
} 
desprovida de sentido, na insuficiência de instrumentos para sua efetiva reivindicação (CAPPELLETTI; GARTH, 1988).

A previsão constitucional dos direitos econômicos e sociais e a sua ampliação coincidente à do Estado de bem-estar converteu o direito ao acesso efetivo à justiça num direito cuja denegação provocaria a de todos os demais. Uma vez destituídos de meios que fizessem impor a sua obediência, os novos direitos sociais e econômicos passariam a meras declarações políticas, sem força normativa. Por essa razão, a organização da justiça civil e particularmente a tramitação processual não pode ser limitada a sua dimensão técnica, formal, como era comum serem concebidas pela teoria processualística liberal (SANTOS, 1989).

O termo acesso à justiça passa a ser incorporado ao vocabulário jurídico pela primeira vez com a publicação dos resultados das pesquisas do Projeto Florença de Acesso à Justiça, coordenado por Cappelletti (NUNES, TEIXEIRA, 2013), que identificou uma série de fatores que precisavam ser superados para que o sistema judicial fosse acessível a todos e produzissem resultados individuais e socialmente justos (CAPPELLETI, GARTH, 1988).

As soluções foram sistematizadas sob a nomenclatura de "ondas" de acesso à justiça, sendo três as ondas de maior impacto no sistema judicial: a primeira "onda" deste movimento foi a assistência judiciária; a segunda representava o respeito às reformas tendentes a proporcionar representação jurídica para os "interesses difusos", em especial nas áreas da proteção ambiental e do consumidor; e a terceira seria um novo enfoque de acesso à justiça, pois seria uma forma de enfrentar os obstáculos ao acesso de modo mais articulado e compreensivo (CAPPELLETTI; GARTH, 1988).

A primeira onda buscou oportunizar serviços jurídicos gratuitos aos hipossuficientes, em razão da premência de assistência de um advogado para a busca da concretização de um direito pelo sistema judicial. A instituição desta garantia implica duas ações concretas: de forma prévia à demanda judicial, informação e orientação; e no decorrer da demanda judicial, a assistência judiciária propriamente dita (BEDIN, SCHONARDIE, 2019).

Sendo assim, não basta a assistência, por meio de advogado, em juízo. Há situações em que a assistência prévia ou extrajudicial seja mais imprescindível, porque a pobreza não é somente econômica, há, também, a pobreza jurídica, ou seja, pobreza de informação. Os hipossuficientes não dominam seus direitos e não detém as informações necessárias para compreenderem o que podem ou não fazer para se protegerem, para galgarem as prerrogativas que o direito substancial poderia lhes conferir (CAPPELLETTI, 1995). 
Neste sentido, a primeira onda torna patente as dificuldades e obstáculos derivados da pobreza. Em razão disso, surge a compreensão de que o acesso à justiça dependeria sobretudo da constatação da existência de um direito, juridicamente exigível; da sabedoria de como ajuizar um processo; e da intenção volitiva de ingressar com uma demanda em juízo. A pesquisa ainda identifica, como empecilho para a concretude do acesso à justiça, a linguagem hermética por parte dos operadores do direito, mecanismos complexos, formalidades excessivas, e os recintos intimidantes, como a ostentação dos tribunais (SADEK, 2014).

Faz-se imprescindível apontar que estas soluções primárias de viabilização do acesso à justiça têm traços marcantes de inclusão social da classe hipossuficiente, quando oferta a possibilidade de demandar os órgãos judiciais sob às expensas do Estado. Tal fato, nas sociedades modernas e complexas, são determinantes para a garantia da isonomia judicial, dado os altos custos dos processos judiciais. Enfatiza-se, ainda, em Cappelletti e Garth (1988) que a assistência judiciária é vital para aqueles que não podem custeá-la.

No Brasil, as bases jurídicas da assistência judiciária são encontradas nas Ordenações Filipinas, com fundamento em princípios cristãos da caridade (WEINTRAUB, 2000). A Constituição de 1934 já trazia em seu âmbito a previsão da assistência judiciária, no artigo 113, no 32 (BRASIL, 1934); assim como a Constituição de 1946, em seu artigo 114, parágrafo 35 (BRASIL, 1946).

Posteriormente, a Lei Federal $n^{\circ} 1.060$ de 1950 estabeleceu as normas para a concessão de assistência judiciária aos necessitados (BRASIL, 1950). Atualmente, os dispositivos que regulavam o tema na Lei $n^{\circ} .: 1.060$ de 1950 foram revogados pela Lei $n^{\circ}$ 13.105 de 2015, que instituiu o Código de Processo Civil em vigor, estando a gratuidade da justiça prevista na Seção IV, que abrange os artigos 98 a 102 (BRASIL, 2015).

Os hipossuficientes, além da barreira econômica, muitas vezes, encontram-se confinados no obstáculo do desconhecimento dos seus próprios direitos, por óbvio, são atormentados não só pela fome, mas também pela miséria e ausência de autodeterminação. Assim, como essas pessoas podem reivindicar direitos que, em sua grande maioria, sequer conhecem (ALVARENGA, 1998)?

Todas estas transformações constituem-se em corolário do novo conceito de acesso à justiça, construído a partir da constitucionalização do direito processual civil, impregnado dos valores imanentes aos direitos fundamentais. 
Faz-se necessária esta reflexão para que o olhar sobre a primeira onda de acesso à justiça seja compreendida sob a complexidade que envolve a população menos favorecida, considerando que não há somente a falta de recursos monetários, mas também a carência do saber, do conhecimento sobre os seus direitos e da forma de exercê-los, quando os detentores do poder (seja econômico ou intelectual) tentam vilipendiá-los.

A segunda onda consistiu no empenho para otimizar o acesso à justiça por meio da instituição de procedimentos jurídicos que viabilizassem a implementação dos interesses difusos, representando-se os interesses coletivos ou grupais (CAPPELLETTI; GARTH, 1988). Enfrentando-se, portanto, a ideia de que o processo civil se restringia a um particular entre dois litigantes, que se reservava à solução de uma demanda entre as partes coincidentes sobre seus próprios interesses individuais (CAVALCANTI, 1999).

Salientando-se que a compreensão convencional de processo civil não facultava oportunidade para a defesa dos direitos difusos (CAPPELLETTI; GARTH, 1988) fazia-se, então, imperiosa a suplantação desta concepção individualista das controvérsias judiciais, autorizando o surgimento de novos mecanismos jurídicos e dispositivos judiciais que admitissem a representação dos interesses coletivos (BEDIN, SCHONARDIE, 2019).

O eixo central da segunda onda, identificada como de representação dos direitos difusos, permanece no prolongamento do direito ao acesso à justiça. Desloca-se da esfera de efetivação dos direitos de natureza individual, para englobar os direitos supraindividuais, representados em grupos, categorias, coletividades (SADEK, 2014).

Percebeu-se que a visão particularista do processo legal não era mais adequada para nova realidade social, que baseava sua organização do Estado de bem-estar social. Esta visão, herdada das sociedades liberais, estava ultrapassada e o direito deveria acompanhar estas transformações. O Estado precisava criar mecanismo de proteção aos indivíduos enquanto classe, em sua concepção coletiva ${ }^{2}$. Mas, como asseveram Cappelletti e Garth (1988) é extremamente necessária a mobilização da iniciativa privada para o enfrentamento das vulnerabilidades inerentes à máquina governamental.

A partir do movimento da segunda onda, foram ampliados os instrumentos de tutela coletiva dos direitos. No Brasil, tal tendência pode ser exemplificada com a publicação da Lei $\mathrm{n}^{\mathrm{o}}$ 7.347, de 24 de julho de 1985, que disciplina a ação civil pública (BRASIL, 1985) e da Lei

\footnotetext{
${ }^{2}$ Para um estudo mais detalhado sobre a proteção dos direitos coletivos no Brasil, dentre muitos outros, consultar BARROSO (2007), GRINOVER (2014) e ZAVASCKI (2005).
} 
Complementar $n^{\circ}$ 80, de 12 de janeiro de 1994, que organiza a Defensoria Pública da União, do Distrito Federal e dos Territórios e prescreve normas gerais para sua organização nos Estados (BRASIL, 1994).

A proteção estatal deve ser apta a conferir a tempestiva e a adequada satisfação de um interesse juridicamente protegido, em favor de seu titular, nas situações em que isso não se verificou de forma natural e espontânea.

De acordo com Piovesan (2021), como bem enfatiza o relatório da ONU, o fortalecimento das Defensorias Públicas, como instituições que concretizam o direito ao acesso à justiça das populações mais vulneráveis, além de outras medidas, como centros integrados de cidadania, justiça itinerante e descentralizada. Quanto à efetividade da prestação jurisdicional, cabe atentar à inovação introduzida pela reforma do Judiciário, ao incluir dentre os direitos fundamentais o direito à razoável duração do processo.

A preocupação com a maior celeridade processual demanda maior racionalização e planejamento do aparato jurisdicional, sendo essencial a elaboração de indicadores para avaliar o funcionamento da justiça e a eficácia da prestação jurisdicional, bem como a adoção de metodologia adequada para a coleta de dados estatísticos, como sugere o relator da ONU. Neste ponto, a própria ONU dispõe-se a prestar assistência técnica e organizar iniciativas de cooperação internacional, abrangendo a identificação de experiências exitosas suscetíveis de serem aqui reproduzidas (PIOVESAN, 2021).

$\mathrm{O}$ ordenamento jurídico brasileiro realizou reformas legislativas que objetivam a eficiência do sistema de garantias dos direitos difusos, mas, para Annoni (2008), o arcabouço normativo já é suficiente e novas alterações legais não ensejam profundas modificações estruturais, pois o modelo existente padece de deficiências organizacionais que solapam a tutela efetiva dos direitos coletivos e difusos.

A terceira onda transcende as anteriores, com uma envergadura mais ampla, concentrando seus esforços em todos os atores processuais, como forma de entender as demandas, mas também para vislumbrar as possibilidades de evita-las, seja através de reformas procedimentais, ou por meio de instrumentos privados de solução de conflitos. Para Cavalcanti (1999), o destaque incide nos meios necessários para a simplificação dos mecanismos judiciais e/ou na instituição de métodos extrajudiciais de resolução de conflitos.

O uso dos métodos adequados de resolução de conflitos, tais como a conciliação e a mediação, são procedimentos significativos para a compreensão e solução dos litígios. 
Basicamente, a principal ideia é diligenciar para o fomento da desburocratização, da simplificação dos métodos, como forma de dirimir essa tendência à burocracia, à morosidade do judiciário (CAPPELLETTI, 1995).

Em outras palavras, o movimento de ampliação do acesso à justiça é conduzido por recursos hábeis a agilizar os mecanismos judiciais internos e, em paralelo, partindo-se para a instituição e introdução de formas extrajudiciais de resolução de conflitos (SADEK, 2014). Por essa razão, simboliza uma considerável, ou até mesmo mais relevante manifestação de uma implacável transmutação do pensamento jurídico e das alterações normativas e institucionais em uma crescente quantidade de países (CAOVILLA, 2003).

Acesso à justiça consubstancia-se no acesso à ordem jurídica, isto é, no alcance da justiça substancial, que somente poderá ser obtida com a apreciação de suas demandas pelo Poder Judiciário, mas não só, é preciso que as pretensões sejam analisadas de forma tempestiva e bem formuladas, com julgamentos que tragam benefícios com relação ao gozo do bem pretendido (DINAMARCO, 2005).

Para Santos (2011), impera no Brasil uma cultura positivista, técnico-burocrática, fundada na ideia de um Direito autônomo, distante dos fenômenos sociais, manifestado em uma cultura generalista, baseado na concepção de que só o julgador tem a prerrogativa ou competência para dirimir os litígios, como aplicador fidedigno da lei.

Consequentemente, é relevante apontar que esta solução tem notórios desafios a serem suplantados, especialmente sobre as ameaças representadas pelas flexibilizações decorrentes da desburocratização, em busca da eficiência e da celeridade, que podem macular as garantias processuais (CAPPELLETTI; GARTH, 1988).

Por fim, verifica-se que muito já se percorreu na busca de soluções para o efetivo acesso à justiça, para que este direito não seja somente formalmente previsto, mas substancialmente exercido, em diversas facetas. No entanto, também se percebe que a operacionalização destas reformas ainda requer um longo caminho de estudos e cautela na implementação, para que os direitos conquistados não sejam sacrificados.

Tamanha é a preocupação não só no âmbito interno, como perante a comunidade internacional, que a temática foi incluída no rol dos direitos humanos, com previsão em diversas convenções internacionais, constituindo-se uma garantia essencial nos sistemas judiciais contemporâneos.

\section{ACESSO À JUSTIÇA COMO DIREITO HUMANO E FUNDAMENTAL}


A concepção contemporânea de direitos humanos foi introduzida pela Declaração Universal de 1948 e adveio da imprescindibilidade de proteção dos indivíduos face às violações destes direitos pelo poder estatal, em resposta às arbitrariedades cometidas durante a Segunda Guerra Mundial, bem como representa a força para o restabelecimento do direitos humanos como arquétipo e referencial ético para regular a ordem Internacional, com a finalidade de efetivar a dignidade humana a nível global (PIOVESAN, 2014).

Os direitos humanos simbolizam uma construção de valores e, neste espaço, os planos regionais e o internacional são complementares e não se admitindo polarizações, pois motivam-se pelo sistema axiológico e principiológicos preconizados na Declaração Universal. O intuito desta sincronia de mecanismos jurídicos garantindo os mesmos direitos é o fortalecimento e a ampliação no amparo e promoção destes direitos (PIOVESAN, 2014).

Partindo destas reflexões, percebeu-se a imprescindibilidade de introduzir neste rol o acesso à justiça que, em um de seus aspectos, representa o direito do indivíduo de buscar no judiciário uma resposta diante da ameaça ou da lesão a um direito (TEODORO, 2014). Neste sentido, a Declaração Universal dos Direitos do Homem, proclamada em 10 de dezembro de 1948 pela Organização das Nações Unidas, traz expressamente que: "VIII. Todo homem tem direito a receber, dos tribunais nacionais competentes, remédio efetivo para os atos que violem os direitos fundamentais que lhe sejam reconhecidos pela constituição ou pela lei” (ONU, 1948).

Reforçando-se a previsão contida na Declaração Universal dos Direitos do Homem, Annoni (2007) destaca que o primeiro documento de envergadura internacional a atestar o direito a efetiva e pronta prestação jurisdicional foi a Convenção Europeia de Direitos Humanos, em seu artigo $6^{\circ}$, I estabelece, desde 1950, que qualquer pessoa tem o direito à prestação jurisdicional em prazo razoável, havendo, inclusive, por intermédio da Corte Europeia de Direitos Humanos, decisões condenatórias de Estados signatários a indenizar os prejudicados pela morosidade excessiva na solução dos litígios (UNITED NATIONS, 1951) 3 .

O Pacto Internacional dos Direitos Civis e Políticos, adotado pela Resolução n. 2.200 A (XXI) da Assembleia Geral das Nações Unidas, em 16 de dezembro de 1966 e ratificado pelo Brasil em 24 de janeiro de 1992, dispõe em seu artigo 14 que todas as pessoas são iguais perante os Tribunais e as Cortes de Justiça e tem o direito de serem ouvidas, com as devidas

\footnotetext{
${ }^{3}$ Para um estudo de outros casos, verificar também, dentre outras, obra de TRINDADE (2017) e PIOVESAN (2014).
} 
garantias (ONU, 1966).

Ainda na esfera normativa de proteção, o acesso à justiça alcança relevância no âmbito do sistema internacional de proteção aos Direitos Humanos e encontra-se resguardando também no sistema regional, consolidada como garantia judicial inserida no Art. $8^{\circ}$. I e 25, I, da Convenção Americana de Direitos Humanos, também conhecida como Pacto de São José da Costa Rica. (TEODORO, 2014). O Brasil é signatário desta Convenção, tendoa ratificado em 1992 por meio do Decreto $n^{\circ} 678$.

$\mathrm{O}$ acesso direto dos indivíduos à jurisdição internacional institui, na contemporaneidade, uma imensa conquista no universo conceitual do Direito, possibilitando ao ser humano pleitear direitos, que lhe são intrínsecos, contra todas as expressões arbitrárias do poder estatal, dando, assim, um substrato ético às normas tanto de direito público interno, como de direito internacional (TRINDADE; ROBLES, 2004).

Nessa ordem de ideias, uma das grandes ameaças aos direitos humanos concentra-se na inaptidão do Estado em garantir sua efetiva realização, em decorrência da ausência de instrumentos de materialização dos direitos reconhecidos (ANNONI, 2003). Portanto, o Estado deve ter uma atuação positiva na efetivação dos direitos humanos, conforme consagra o artigo X da Declaração Universal dos Direitos do Homem.

Internamente, a garantia à jurisdição já se encontrava presente no Direito Constitucional pátrio, como princípio, desde a Constituição do Império, sendo deduzido das normas de estruturação do Poder Judiciário. Com a Constituição de 1946, o princípio é convertido em regra, consagrando-se na positivação no artigo 141 , parágrafo $4^{\circ}$ da Constituição de 1946 (SILVA, 1999).

A proteção da referida regra fundamental de forma contínua manteve-se nas constituições posteriores, mas sofreu uma redução com a edição do Ato Institucional $\mathrm{n}^{\circ}$ 06, de 01 de fevereiro de 1969, que, em seu artigo $4^{\circ}$, excluiu da apreciação judicial todos os atos praticados pelo comando da revolução, bem como seus respectivos efeitos (MOURA, 2007).

Com o advento da Constituição de 1988, um conjunto mais abrangente de garantias, formas e mecanismos processuais, robusteceu a guarida dos direitos subjetivos (BONAVIDES, 2011), ampliando-se o direito de acesso ao Judiciário para antes da efetivação da lesão, possibilitando o ingresso em juízo para resguardar os direitos ameaçados (SILVA, 1999).

No entanto, é preciso reforçar a ideia de que o direito de acesso à justiça, 
consubstanciado no dispositivo constitucional, não pode e nem deve significar apenas o direito formal de evocar a jurisdição, mas o direito a uma decisão justa, pois, caso assim não seja, a apreciação judicial se esvazia de conteúdo valorativo (SILVA, 1999).

$\mathrm{O}$ acesso à justiça como direito fundamental assegurado no Texto Constitucional de 1988 assume um contexto com fortes repercussões sociais que transformou-se em amálgama da função inclusiva do Poder Judiciário no Século XXI, atrelando-se intimamente às formas consensuais de soluções de conflitos.

O acesso ao Judiciário é uma das formas de acesso à justiça, mas não só por este meio, esta garantia desvela-se, também, através de um processo judicial cercado das tutelas legais e efetivas dos direitos violados ou ameaçados (GRINOVER, 2006), a mera propositura da ação judicial não equivale ao acesso à justiça (DINAMARCO, 2005).

A complexa questão do acesso à justiça não pode ser entendida nas tímidas balizas do acesso aos órgãos judiciais, pois a problemática não se restringe apenas na viabilização do acesso à Justiça enquanto instituição estatal, mas também em oportunizar o acesso à ordem jurídica justa (WATANABE, 1988).

Neste mesmo sentido, o termo jurisdição, que normalmente, atrela-se a presença do Estado, hoje comporta uma nova significação, afastando-se da orientação monopolística oficial e desdobrando-se para outras instâncias, ofertando justiça por outras vias e perante outros atores da cena judiciária (MANCUSO, 2014).

Portanto, o acesso à justiça deve revela-se no acesso ao procedimento justo, ao devido processo legal, a garantia de acesso à imparcialidade judicial, e a uma Justiça equitativa, contraditória, dialética, cooperativa, que coloque à disposição dos partícipes todos os instrumentos e os meio necessários para amparar suas razões, produção de provas e formação do convencimento do julgador (MARINONI, 2007).

Por intermédio da Emenda Constitucional $\mathrm{n}^{\mathrm{o}} .:$ 45, de 30 de dezembro de 2004, o Brasil introduziu, no rol constitucional de direitos fundamentais, a garantia à razoável duração do processo, normatizando sua preocupação em combater a lentidão que afronta a justiça no país (ANNONI, 2007).

Esta inclusão, reforça o compromisso que o Estado, e todos os órgãos e instituições, públicas e privadas, firmaram de efetivar este direito, envidando esforços para a concretização deste direito humano e fundamental do acesso à justiça na ordem democrática brasileira. 
$\mathrm{O}$ acesso à justiça na qualidade de garantia assegurada pelo Art. $5^{\circ}$, inciso XXXV da $\mathrm{CF} / 88$ é o mecanismo propulsor da exigência de cumprimento por parte do Estado dos direitos fundamentais declarados constitucionalmente e que não estão sendo aplicados, possibilitando a exposição das pessoas que se encontrem em situações de indignidade, subalternidade e exclusão socioeconômica.

A realidade contemporânea brasileira demonstra que o acesso à justiça desempenha papel fundamental no acesso aos direitos fundamentais. Decisões judiciais em temas atinentes ao acesso à justiça envolvem questões de alta complexidade técnico-jurídica.

Para Boaventura de Sousa Santos (2011), muitos dos litígios que hoje chegam aos tribunais deve-se ao desmantelamento do Estado Social (direito laboral, previdência social, educação, saúde, etc). A Suécia, provavelmente detentora do melhor sistema de Estado de bem-estar da Europa tem baixíssima litigação judicial; a Holanda é, também, um dos países com uma das mais baixas taxas de litigação da Europa. O que significa que a litigância relaciona-se com culturas jurídicas e políticas, mas também com o nível de efetividade da aplicação dos direitos e com a existência de estruturas administrativas que sustentem essa aplicação.

A mera formalização deste direito na Constituição, no entanto, não enseja as transformações que promovam a reorientação do arranjo organizacional existente no Poder Judiciário. Somente a modificação estrutural dos cerceamentos sistêmicos pode, de fato, implicar num alargamento do acesso da população à justiça, por meio da celeridade das decisões judiciais (RIBEIRO, 2008).

Entendendo a importância de uma restruturação do Judiciário na promoção do acesso à justiça, o Conselho Nacional de Justiça (CNJ) desenvolveu o Índice de Acesso à Justiça $(\mathrm{IAJ})^{4}$, em parceria com o Programa das Nações Unidas para o Desenvolvimento (PNUD), por meio da coleta de dados como forma de mensurar os esforços de promoção desse acesso, bem como para a introdução de políticas judiciárias baseadas em evidências atuais (CNJ, 2021).

Ao conceber o IAJ, duas espécies de capitais foram idealizadas: o Capital Humano e o Capital Institucional. O primeiro foi seccionado em dois aspectos - Cidadania e População

\footnotetext{
${ }^{4}$ O Índice de Acesso a Justiça foi disponibilizado no dia 24 de fevereiro de 2021 no portal do Programa das Nações Unidas para o Desenvolvimento. Disponível em: https://www.cnj.jus.br/wpcontent/uploads/2021/02/Relatorio_Indice-de-Acesso-a-Justica_LIODS_22-2-2021.pdf. Acesso em: 12 abr. 2021.
} 
- e o segundo trata do Judiciário. Cada Capital foi fragmentado em dimensões e essas, em características - variáveis e/ou indicadores. A Figura 1 retrata a hierarquia mencionada, e as subdivisões a seguir descrevem, pormenorizadamente, os Capitais e suas respectivas dimensões e aspectos (CNJ, 2021).

Figura 1: Representação esquemática do IAJ e seus componentes.

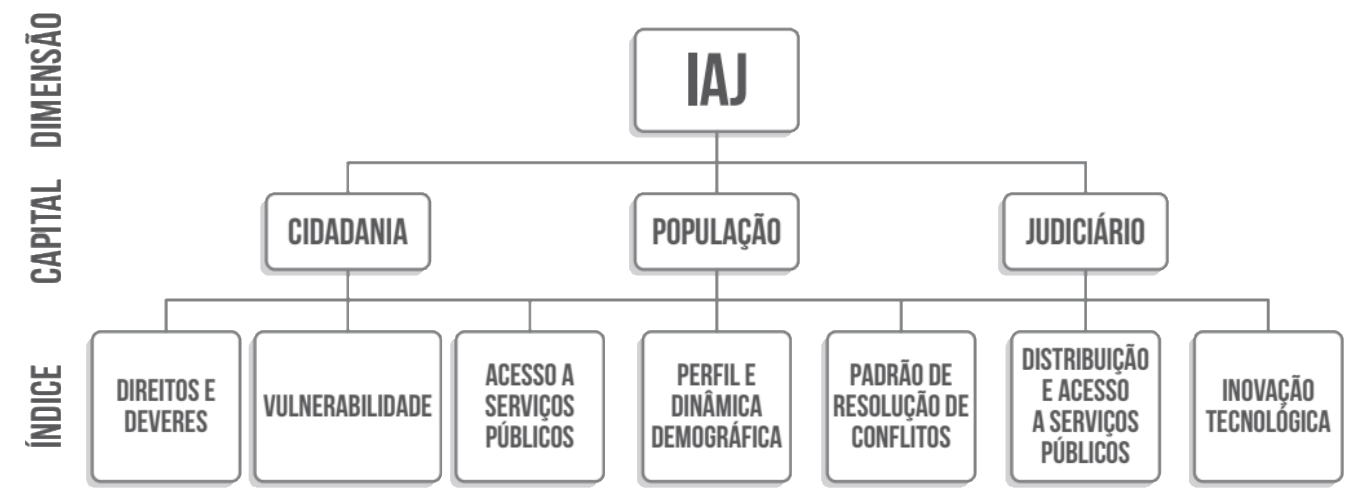

Fonte: CNJ, 2021.

Percebe-se que cada um dos capitais contém diferentes dimensões, sendo a capacidade de reconhecer direitos e deveres, a vulnerabilidade e o acesso a serviços públicos, as dimensões do Capital Humano (Cidadania); já o Capital Humano (População), possui uma única dimensão, que trata do perfil da população e sua dinâmica demográfica; fechando a tríade, o Capital Institucional (Judiciário) traz como dimensões o padrão de resolução de conflitos, a distribuição e o acesso a serviços públicos e a inovação tecnológica (CNJ, 2021).

Retrata-se, assim, que os aspectos ora debatidos sobre a problemática do acesso à justiça estão contemplados no IAJ, apontando uma ampliação da acepção do termo quando da coleta dos dados referentes ao entendimento dos direitos e das vulnerabilidades do Capital Humano, bem como considerando os aspectos organizacionais do Poder Judiciário.

É preciso ir além neste entendimento e atentar para o fato de que esta transformação estrutural deve partir da mudança de perspectiva da própria educação jurídica, voltando-se o ensino para a promoção do acesso à justiça, em suas múltiplas dimensões.

\section{ENSINO JURÍDICO COMO AMBIÊNCIA PRIMORDIAL DE FOMENTO DO ACESSO À JUSTIÇA}

A melhora dos meios e a racionalização dos serviços se fazem primordiais para a efetivação do direito constitucional do acesso à justiça, com a constante busca do Judiciário em reduzir custos sem mitigar a acessibilidade, "essa 'terceira onda' de reforma inclui a advocacia, judicial e extrajudicial, seja por meio de advogados particulares ou públicos, mas 
vai além.

Dirige-se ao conjunto geral de instituições e mecanismos, pessoas e procedimentos utilizados para processar e mesmo prevenir disputas nas sociedades modernas. Nós o denominamos 'o enfoque do acesso à Justiça' por sua abrangência” (CAPELLETI; GARTH, 1998).

Nesta seara, por meio do desenvolvimento de estudos sobre a temática, Economides (1999), que já havia feito comentários à segunda versão da série Acesso à Justiça do "Projeto Florença", identifica mais uma onda ao movimento de acesso à justiça, que seria a quarta onda, representada pelo acesso dos operadores do direito (inclusive dos que trabalham no sistema judicial) à justiça.

Esta nova perspectiva analítica deriva do fato de que a essência do problema não está mais limitada ao acesso dos cidadãos à justiça, pois já há mecanismos que asseguram este acesso, mas que inclui também o acesso dos próprios advogados à justiça. E tal acesso se daria através da formação acadêmica do estudante de direito, que deveria moldar o caráter profissional dos estudantes, transmitindo os valores da transformação social que a lei pode fomentar nos indivíduos (ECONOMIDES, 1999).

Destaca-se que, em levantamento feito pelo Conselho Federal da Ordem dos Advogados do Brasil - CFOAB, o Brasil é o país com o maior número de cursos de graduação em Direito no mundo e a criação de novos cursos jurídicos se intensificou na década do ano 2000, ficando em torno de 1.100 no final da última década, em 2017, havia 1.203 cursos de graduação em Direito, espalhados por 923 IES, de acordo com o Censo da Educação Superior, do Inep. Entretanto, esta quantidade não é sinônimo de qualidade, como traduz o estudo exame de ordem em números de 2020, publicado recentemente pelo $\mathrm{CFOAB}^{5}$.

A excessiva dogmatização do ensino jurídico ao longo dos anos vem distanciando o Direito do seu papel transformador da realidade social e, de certo modo, vem mitigando os direitos fundamentais e a própria força normativa da Constituição Federal. Portanto faz-se necessário um redimensionamento da importância dos operadores do Direito para a sociedade, e tal feito somente será possível através da reestruturação da educação jurídica.

Neste ensejo, verifica-se que alguns dos problemas que se apresentam ao efetivo acesso à justiça decorrem de uma deficiência na formação profissional de diversos operadores jurídicos. O formalismo verificado na educação jurídica tem origem em partes na formação

\footnotetext{
${ }^{5}$ Disponível em: https://examedeordem.oab.org.br/DadosEstatisticos. Acesso em: 14 abr. 2021.
} 
positivista que não permite aos bacharéis em Direito o desenvolvimento do raciocínio jurídico e do senso crítico necessários para se apropriarem de sua função na sociedade, pois não se pode ter um efetivo acesso à justiça sem profissionais devidamente qualificados; não se pode ter profissionais qualificados sem um bom nível de ensino. (RODRIGUES, 1994).

A educação jurídica difundida em larga escala dentro da comunidade acadêmica gira em torno de uma abordagem legalista e manualizada do Direito (STRECK, 2014), com a introdução dos precedentes judiciais como padrões jurisprudenciais a serem seguidos, dentro de um ambiente de ensino impositivo e pouco dialético, desestimulando a capacidade crítica e criativa do estudante de direito que devem estar preparados para as rápidas mudanças da sociedade contemporânea e clientes cada vez mais exigentes à procura de profissionais ágeis e eficientes.

Nas lições de Rodrigues (1994), o problema do acesso à justiça transcende a seara jurídico-processual, pois perpassa por outras instâncias, sendo importante ter esta consciência para o progresso da equacionalização destas esferas, seja no contexto político, econômico, cultural. $\mathrm{O}$ operador do direito que não percebe este aspecto, continuará a enxergar a questão do acesso à justiça apenas como problemas a serem resolvidos por meio da criação de novos instrumentos técnico-processuais ou da correção dos existentes, contribuindo para a manutenção e propagação do status quo.

É preciso vislumbrar o sistema processual não somente como um instrumento de solução de conflitos, seja os intersubjetivos ou mesmo difusos, coletivos ou individuais homogêneos, mas igualmente, e de fundamental importância, como instrumento político de realização da justiça social, escopo maior do estado contemporâneo (RODRIGUES, 1994).

Esse condicionamento cultural precisa mudar, fomentando a importância de se evitar disputas, pois no universo de todos os conflitos surgidos na sociedade, a grande maioria deles é resolvida consensualmente, por negociação direta entre as partes ou com o auxílio de terceira pessoa (SALLES, 2010).

A mutação paradigmática do ensino jurídico revela a sua particularidade dinâmica e transformadora. A realidade jurídica na conjuntura do pós-positivismo e da pós-modernidade é bastante complexa, não podendo ser reduzida somente aos paradigmas dantes vigentes quando da elaboração das atuais matrizes curriculares dos cursos jurídicos (MARQUES JÚNIOR, 2013).

Os profissionais jurídicos necessitam sensibilidade e racionalidade na formação de 
um papel inclusivo nesta promoção da solução de controvérsias, sem que seja preciso perpassar o Judiciário para se alcançar o resultado desejado pelas partes, fato que pode ser obtido por meio de soluções criativas que só uma formação acadêmica pós-crítica, propositiva e voltada para a cultura do consenso podem proporcionar ao bacharel em direito.

É neste ensejo que as novas DCNs incluem a disciplina de formas consensuais de resolução de conflitos para serem trabalhadas dentro dos cursos de direito (BRASIL, 2018), pois acredita-se que com o fomento de práticas colaborativas, viabilizando a resolução das demandas de forma consensual como, por exemplo, por meio da autocomposição, mediação e arbitragem, ou seja, dos serviços jurídicos preventivos, o resultado inevitável será a melhoria do acesso dos cidadãos à justiça (ECONOMIDES, 1999).

O panorama hermenêutico jurídico-constitucional de entendimento dos valores peculiares ao ensino nos Cursos de Direito serve de alicerce ao encadeamento entre os atributos de sensibilidade e racionalidade demandados do profissional jurídico (especialmente o advogado) e a complexidade dos novos fenômenos sociais surgidos no cenário da pósmodernidade e carecedores de proteção à luz dos ditames difundidos no pós-positivismo (MARQUES JÚNIOR, 2013).

Neste contexto, a questão do acesso à justiça, como perspectiva de os indivíduos terem as suas demandas solucionadas institucionalmente no âmbito do judiciário de forma célere e sem quaisquer alteridades, integra-se à própria ideia de normas e organizações da cidadania civil (RIBEIRO, 2008).

Deve-se buscar, portanto, a solução das controvérsias através de sua simplificação, desburocratização e desformalização. Isso pode ser feito em dois níveis, tanto na alteração da legislação, como por meio da mudança de mentalidade dos aplicadores do Direito. Essa última deve ter por base a consciência de que a forma é um meio para atingir o objetivo e não um fim em si mesmo (RODRIGUES, 1994).

Conforme as diretrizes oriundas do direito fundamental de acesso à justiça, deve-se fomentar as formas consensuais de solução de conflitos e colocar a formação de profissionais jurídicos propositivos e pós-críticos no centro das agendas para elaboração de práticas pedagógicas, já que a educação assume papel vetorial na efetividade dos demais direitos fundamentais.

\section{CONSIDERAÇÕES FINAIS}

Dentro desta perspectiva, vislumbra-se que a educação jurídica é a via adequada para 
a promoção do efetivo acesso à justiça aos jurisdicionados, pois somente através da mudança da cultura jurídica do litígio para a cultura da importância do consenso, onde não há ganhadores e perdedores, mas sujeitos colaborativos para a promoção da solução do conflito, é que atingiremos os objetivos de transformação da realidade pelo operador do direito, como verdadeiros agentes de afirmação da cidadania e da própria democracia, através da aplicação do Direito.

Conclui-se, portanto, que o olhar para o ensino deve transcender, buscando-se adequar o ensino para a contemplação destes novos obstáculos ao acesso à justiça, construindo-se a cultura do consenso desde o nascedouro da formação jurídica, formando profissionais capacitados para oferecer à sociedade soluções estratégicas, que reduza os custos de transação e conformidade, com a substancial diminuição do tempo de espera do provimento jurisdicional, o que proporcionará a efetiva concretização deste direito fundamental pelo jurisdicionado.

\section{REFERÊNCIAS}

ALVARENGA, Lucia Barros Freitas de. Direitos Humanos, dignidade e erradicação da pobreza. Brasília: Jurídica, 1998.

ANNONI, D. Direitos humanos e acesso à justiça no direito internacional: responsabilidade internacional do Estado. Curitiba: Juruá, 2003.

ANNONI, D. Acesso à justiça e direitos humanos: a Emenda Constitucional 45/2004 e a garantia a razoável duração do processo. Revista Direitos Fundamentais \& Democracia, Curitiba, v. 2, 2007. Disponível em:

https://revistaeletronicardfd.unibrasil.com.br/index.php/rdfd/article/view/190/182. Acesso em: 21 jul. 2020.

ANNONI, D. O direito humano de acesso à justiça no Brasil. Porto Alegre: Sergio Antonio Fabris Ed., 2008.

BEDIN, G.; SCHONARDIE, E. Os Direitos Humanos e o Acesso à Justiça: Uma Análise Histórico-Conceitual de um Direito Fundamental para a Convivência Humana Pacífica. Revista Direito em Debate, Porto Alegre, v. 27, n. 50, p. 75-86, 6 fev. 2019. Disponível em: https://www.revistas.unijui.edu.br/index.php/revi stadireitoemdebate/article/view/8050/5973. Acesso em: 21 jul. 2020.

BRASIL. Lei 13.105, de 16 de março de 2015. Código de Processo Civil. Brasília, DF, Senado, 2015. Disponível em: http://www.planalto.gov.br/ccivil_03/_ato20152018/2015/lei/113105.htm. Acesso em: 21 jul. 2020.

BRASIL. Constituição (1934). Constituição da República dos Estados Unidos do Brasil, Rio de Janeiro, Assembleia Nacional Constituinte, 1934. Disponível em:

http://www.planalto.gov.br/ccivil_03/constituicao/constituicao34.htm. Acesso em: 14 abr.

Revista de Formas Consensuais de Solução de Conflitos | e-ISSN: 2525-9679 | Encontro Virtual | 
2021.

BRASIL. Constituição (1946). Constituição dos Estados Unidos do Brasil, Rio de Janeiro, Assembleia Constituinte, 1946. Disponível em:

http://www.planalto.gov.br/ccivil_03/constituicao/constituicao46.htm. Acesso em: 21 jul. 2020.

BRASIL. Constituição (1988). Constituição da República Federativa do Brasil. Brasília, DF, Senado, 1988. Disponível em:

http://www.planalto.gov.br/ccivil_03/constituicao/constituicao.htm. Acesso em: 21 jul. 2020.

BRASIL. Decreto Lei n. 678 de 6 de novembro de 1992.

Promulga a Convenção Americana sobre Direitos Humanos (Pacto de São José da Costa Rica), de 22 de novembro de 1969, Brasília: DF: Presidência da República. Disponível em: http://www.planalto.gov.br/ccivil_03/decreto/d0678.htm. Acesso em: 21 jul. 2020.

BRASIL. Ministério da Educação. Resolução no 5 , de 17 de dezembro de 2018. Institui as Diretrizes Curriculares Nacionais do Curso de Graduação em Direito e daì outras providências. 2018. Disponível em:

http://portal.mec.gov.br/index.php?option=com_docman\&view=download\&alias=104111 rces005-18\&category_slug=dezembro-2018-pdf\&Itemid=30192. Acesso em: 20 mar. 2020.

BRASIL. Lei n. 7.347, de 24 de julho de 1985. Disciplina a ação civil pública de responsabilidade por danos causados ao meio ambiente, ao consumidor, a bens e direitos de valor artístico, estético, histórico, turístico e paisagístico (vetado) e dá outras providências. Disponível em: https://www2.camara.leg.br/legin/fed/lei/1980-1987/lei-7347-24-julho-1985356939-publicacaooriginal-1-pl.html. Acesso em: 10 abr. 2021.

BONAVIDES, Paulo et al. Curso de direito constitucional. Sao Paulo: Malheiros, 2011.

CAPPELLETTI, Mauro; GARTH, Bryant. Acesso à justiça. Porto Alegre: Sérgio Antônio Fabris, 1988.

CAPPELLETTI, M. Acesso à justiça. Porto Alegre: Revista dos Tribunais, 1995.

CAVALCANTI, R. B. Cidadania e acesso à justiça. São Paulo: Idesp, 1999.

CAOVILLA, M. A. Acesso à justiça e cidadania. Chapecó: Argos, 2003.

COUNCIL OF EUROPE. Convenção Europeia dos Direitos do Homem. Conselho da Europa, França, 4 nov. 1950. Disponível em: https://www.echr.coe.int/Documents/Convention_POR.pdf. Acesso em: 21 jul 2020.

Conselho Nacional de Justiça. Índice de acesso à justiça. Brasília: CNJ, 2021. Disponível em: https://www.cnj.jus.br/wp-content/uploads/2021/02/Relatorio_Indice-de-Acesso-aJustica_LIODS_22-2-2021.pdf. Acesso em: 10 abr. 2021.

DINAMARCO, Cândido Rangel. A instrumentalidade do processo. 12a ed., São Paulo: Malheiros, 2005. 
ECONOMIDES, Kim. Lendo as ondas do "movimento de acesso à justiça": epistemologia versus metodologia? In: PANDOLFI, Dulce; CARVALHO, José Murilo de; CARNEIRO, Leandro Piquet; GRYNSZPAN, Mário (orgs.). Cidadania, justiça e violência. Rio de Janeiro: Fundação Getúlio Vargas, 1999. Disponível em: http://www.cpdoc.fgv.br. Acesso em: 15 maio. 2020.

GRINOVER, Ada Pellegrini; et al. In Tutela Coletiva: 20 anos da Lei da Ação Civil Pública e do Fundo de Defesa de Direitos Difusos, 15 anos do Código de Defesa do Consumidor / Paulo Henrique dos Santos Lucon (coord). - São Paulo: Aplas, 2006.

GRINOVER, A. P. et al (Coord.). Processo coletivo: do surgimento à atualidade. São Paulo: Revista dos Tribunais, 2014.

JUNQUEIRA, E. B. Acesso à Justiça: um olhar retrospectivo. Revista Estudos Históricos, Rio de Janeiro, v. 9, n. 18, p. 389-402, dez. 1996. ISSN 2178-1494. Disponível em: http://bibliotecadigital.fgv.br/ojs/index.php/reh/article/view/2025. Acesso em: 21 jul. 2020.

MANCUSO, Rodolfo de Camargo. A resolução dos conflitos e a função judicial no contemporâneo Estado de Direito. - 2 ed. ver., atual. e ampl. - São Paulo: Revista dos Tribunais, 2014.

MARINONI, Luiz Guilherme. Teoria Geral do Processo. 2a ed., São Paulo: Revista dos Tribunais, 2007.

MARQUES JÚNIOR, William Paiva. Diretrizes do ensino jurídico na intercomunicação com a compulsoriedade do exame da Ordem dos Advogados do Brasil. 2013. Disponível em: http://www.revistadireito.ufc.br/index.php/revdir/article/view/48/54. Acesso em: 29 jul. 2020.

MOURA, Caio Roberto Souto de. O princípio da inafastabilidade do controle jurisdicional e a Justiça Desportiva: um caso de antinomia jurídica. Revista de Doutrina TRF4, 2007.

NUNES, Dierle; TEIXEIRA, Ludmila. Acesso à justiça democrático. Brasília: Gazeta Jurídica, p. 44, 2013.

ORGANIZAÇÃO DAS NAÇÕES UNIDAS. Declaração Universal dos Direitos Humanos. Assembleia Geral das Nações Unidas, Paris, 10 dez. 1948. Disponível em:

https://nacoesunidas.org/wp-content/uploads/2018/10/DUDH.pdf. Acesso em: 21 jul. 2020.

ORGANIZAÇÃO DOS ESTADOS AMERICANOS. Convenção Americana de Direitos Humanos. San Jose, Costa Rica, 22 nov. 1969. Disponível em:

https://www.cidh.oas.org/basicos/portugues/c.convenca o_americana.htm. Acesso em: 21 jul 2020.

PIOVESAN, F. Direitos humanos e justiça internacional: um estudo comparativo dos sistemas regionais europeu, interamericano e africano. 5. ed. São Paulo: Saraiva Jur, 2014.

PIOVESAN, Flávia. Por uma justiça acessível, efetiva e democrática. Disponível em: http://www.cartamaior.com.br/?/Coluna/Por-uma-Justica-acessivel-efetiva-e- 
democratica/21925. Acesso em: 13 abr. 2021.

RODRIGUES, Horácio Wanderlei. Acesso à Justiça no Direito Processual Brasileiro. São Paulo: Acadêmica, 1994.

RIBEIRO, L. M. L. A emenda constitucional 45 e a questão do acesso à justiça. Revista Direito GV, [s.l.], v. 4, n. 2, p. 465-491, jul. 2008. ISSN 2317-6172. Disponível em: http://bibliotecadigital.fgv.br/ojs/index.php/revdireito gv/article/view/35160/33965. Acesso em: 21 jul. 2020.

SADEK, M. T. Acesso à justiça: um direito e seus obstáculos. São Paulo, Revista USP, n. 101, p. 55-66, 30 maio 2014. Disponível em: http://www.revistas.usp.br/revusp/arti cle/view/87814. Acesso em: 21 jul. 2020.

SALLES, Carlos Alberto de et al. A experiência do Núcleo de Estudos de Meios de Solução de Conflitos (NEMESC). Revista Direito GV, São Paulo, v. 6, n. 1, p. 67-094, jan. 2010. Disponível em:

http://bibliotecadigital.fgv.br/ojs/index.php/revdireitogv/article/view/24200/22975. Acesso em: 24 maio. 2020.

SANTOS, B S. Introdução à sociologia da administração da justiça. In: FARIA, José Eduardo (Org.). Direito e justiça: a função social do Judiciário. São Paulo: Ática, 1989.

SANTOS, Boaventura de Sousa. Para uma revolução democrática da justiça. $3^{\text {a }}$ - edição. São Paulo: Cortez, 2011.

DA SILVA, José Afonso. Acesso à justiça e cidadania. Revista de direito administrativo, v. 216, p. 9-23, 1999.

STRECK, Lenio Luiz. Jurisdição constitucional e decisão jurídica. 4. ed. São Paulo: Revista dos Tribunais, 2014.

TEODORO, W. S. Proteção ampla de acesso à justiça dos órgãos interamericanos de direitos humanos. Espaço Jurídico Journal of Law [EJJL], v. 15, n. 1, p. 103-118, 28 maio 2014. Disponível em: https://portalperiodicos.unoesc.edu.br/espacojuridico/article/view/3616/255. Acesso em: 21 jul. 2020.

TRINDADE, Antônio Augusto Cançado. Princípios do direito internacional contemporâneo. 2. ed. rev. atual. Brasília: FUNAG, 2017.

TRINDADE, A. C.; ROBLES, M. E. V. El futuro de la Corte Interamericana de Derechos Humanos. 2. ed. atual. e ampl., San José, Costa Rica, Corte Interamericana de Direitos Humanos/ACNUR, 2004.

UNITED NATIONS. Reports of International Arbitral Awards. Claims commissions, v. IV, p. $282 \square 312$, 1951. Disponível em: https://legal.un.org/riaa/volumes/riaa_IV.pdf. Acesso em 21 jul. 2020.

WATANABE, Kazuo. Acesso à justiça e sociedade moderna. ln: GRINOVER, Ada Pellegrini 
et al. (coord.). Participação e processo. São Paulo: Revista dos Tribunais, 1988. p. 128-135.

WEINTRAUB, A. B. V. 500 anos de assistência judiciária no Brasil. In: Revista da

Faculdade de Direito, Universidade de São Paulo, v. 95, p. 241-249, 2000. Disponível em: https://www.revistas.usp.br/rfdusp/article/download/67467/70077. Acesso em: 21 jul. 2020.

ZAVASCKI, T. Processo coletivo: tutela de direitos coletivos e tutela coletiva de direitos. 2005. 295 f. Tese (Doutorado em Direito) - Universidade Federal do Rio Grande do Sul, Porto Alegre, 2005. Disponível em:

https://www.lume.ufrgs.br/bitstream/handle/10183/4574/000502398.pdf. Acesso em: 21 Jul. 2020. 